\title{
MAPEAMENTO DE UNIDADES DE RELEVO NA MÉDIA SERRA DO ESPINHAÇO MERIDIONAL - MG
}

\author{
Éric Andrade Rezende* \\ André Augusto Rodrigues Salgado**
}

\section{RESUMO}

O presente trabalho propõe um mapeamento de unidades de relevo para a porção sul do terço médio da Serra do Espinhaço Meridional. As unidades de relevo foram delimitadas a partir da análise integrada de cartas temáticas e imagens de satélite que permitiram observar variações na morfologia, na altimetria, na declividade, na litoestrutura e na organização da rede de drenagem. A etapa de cartografia digital, processada no software ArcGis 9.2, se baseou na utilização de produtos SRTM (Shuttle Radar Topography Mission). Os procedimentos metodológicos também incluíram trabalhos de campo e pesquisa bibliográfica. Foi empregada a taxonomia do mapeamento geomorfológico proposta pelo IBGE (2009), através da qual foram individualizadas quatorze Unidades Geomorfológicas. As unidades estão distribuídas entre cinco diferentes compartimentos do seguinte modo: dois planaltos, duas escarpas, seis depressões, três conjuntos de cristas e um conjunto de patamares. Foi possível observar que a disposição geral das unidades reflete o forte controle litoestrutural imposto ao relevo regional. Destaca-se a resistência diferenciada das diversas litologias frente aos processos denudacionais e a influência da neotectônica na geomorfogênese.

PALAVRAS CHAVE: Serra do Cipó; unidades de relevo, cartografia geomorfológica, SRTM.

\section{ABSTRACT}

This paper proposes a mapping of landforms units for the southern portion of the middle third of the Serra do Espinhaço Meridional. The landforms units were delineated from the integrated analysis of thematic maps and satellite images that allowed the observation of changes in morphology, altimetry, slope, lithostructure and organization of the drainage network. The step of digital mapping, processed in the software ArcGIS 9.2, was based in the use of SRTM products (Shuttle Radar Topography Mission). The methodological procedures also included field work and literature research. The taxonomy of geomorphological mapping proposed by IBGE (2009) was applied, through which fourteen Geomorphologycal Units were individualized. The units are distributed amongst five different compartments as follows: two plateaux, two escarpments, six depressions, three sets of ridges and one set of intermediate levels. It was observed that the general layout of the units reflects the strong lithostructural control forced to regional relief. The differentiated resistance of the various lithologies in relation to denudational processes and the influence of neotectonic on landscape evolution are noteworthy.

KEYWORDS: Serra do Cipó; landforms units, geomorphological mapping, SRTM. 


\section{Introdução}

O relevo é, entre os componentes do meio físico, um dos principais definidores de unidades ambientais. Sua compartimentação está frequentemente em estreita relação com a distribuição dos demais atributos formadores da paisagem, como, por exemplo, os solos e a vegetação. Deste modo, os estudos e mapeamentos geomorfológicos são de grande valia na definição das melhores formas de uso e manejo de determinada área. Ross (1992) afirma que os estudos geomorfológicos e ambientais, quer sejam eles detalhados ou de âmbito regional, atendem às necessidades político-administrativas e funcionam como instrumento de apoio técnico aos mais diversos interesses políticos e sociais.

As investigações geomorfológicas, notadamente a cartografia do relevo, ganham importância ainda maior em áreas prioritárias para preservação ambiental, como a Serra do Espinhaço, que comporta elevado grau de biodiversidade e foi definida recentemente como Reserva da Biosfera (GONTIJO, 2008). Neste contexto, inserese o presente trabalho que objetiva realizar o mapeamento das unidades de relevo de uma porção da Serra do Espinhaço Meridional e adjacências. O trecho estudado corresponde a porção sul do terço médio desta serra e abrange parte dos municípios de Baldim, Santana do Riacho, Morro do Pilar, Conceição do Mato Dentro, Congonhas do Norte, Santana de Pirapama, Dom Joaquim e Jequitibá. A área é delimitada pelos paralelos $18^{\circ} 53^{\prime} 00^{\prime \prime}$ e $19^{\circ} 15^{\prime} 52^{\prime \prime}$ de latitude sul e pelos meridianos $43^{\circ} 20^{\prime} 15^{\prime \prime}$ e $43^{\circ} 51^{\prime} 00^{\prime \prime}$ de longitude oeste (Fig. 1). No mapeamento pretende-se individualizar zonas com um padrão de formas semelhante, sendo essa proposta mais adequada à escala regional. O trabalho visa ainda descrever cada uma das unidades, abrangendo aspectos morfológicos, hipsometria, declividades, litoestrutura e rede de drenagem.

A proposta de trabalho se torna ainda mais relevante pela ausência de mapeamentos de relevo na maior parte da área e pela própria escassez de estudos de cunho geomorfológico em uma região de características ambientais tão singulares. Os mapeamentos de relevo já realizados na Serra do Espinhaço Meridional concentraram suas atenções na extremidade sul da cadeia montanhosa (GONTIJO, 1993) ou mais ao norte, nas imediações do Planalto de Diamantina (ABREU, 1982; FONSECA, 2008). Deste modo, a presente pesquisa preencherá uma lacuna ainda não mapeada.

\section{Caracterização da Área}

A Serra do Espinhaço é a faixa orogênica pré-cambriana mais extensa e contínua do território brasileiro, cuja porção meridional representa um orógeno de colisão edificado no Mesoproterozóico (ALMEIDA-ABREU \& RENGER, 2002). Essa faixa orogênica de direção NNW-SSE limita o sudeste do Cráton do São Francisco e foi reativada no fim do Neoproterozóico, seguindo a mesma compartimentação da deformação deixada pela orogênese mesoproterozóica. É composta essencialmente por litologias do Supergrupo Espinhaço, principalmente rochas quartzíticas e, subordinadamente, rochas filíticas, conglomeráticas e vulcânicas de caráter básico e ácido (Fig. 2) (ALMEIDA-ABREU, 1995). A oeste do cinturão de cavalgamentos ocorrem metassedimentos neoproterozóicos do Grupo Bambuí, enquanto na extremidade leste da área de estudo predominam gnaisses arqueanos do Complexo Dona Rita (GROSSI-SAD et al., 1997).

Gontijo (1993) afirma que a serra individualiza-se pela predominância de formas de relevo que guardam as características estruturais, decorrentes de uma tectônica compressiva com cavalgamentos em rochas essencialmente quartzíticas. As formas de relevo resultantes de sua esculturação pela dissecação fluvial são representadas, majoritariamente, por cristas, escarpas e vales profundos adaptados às direções tectônicas e estruturais (SAADI, 1995). 


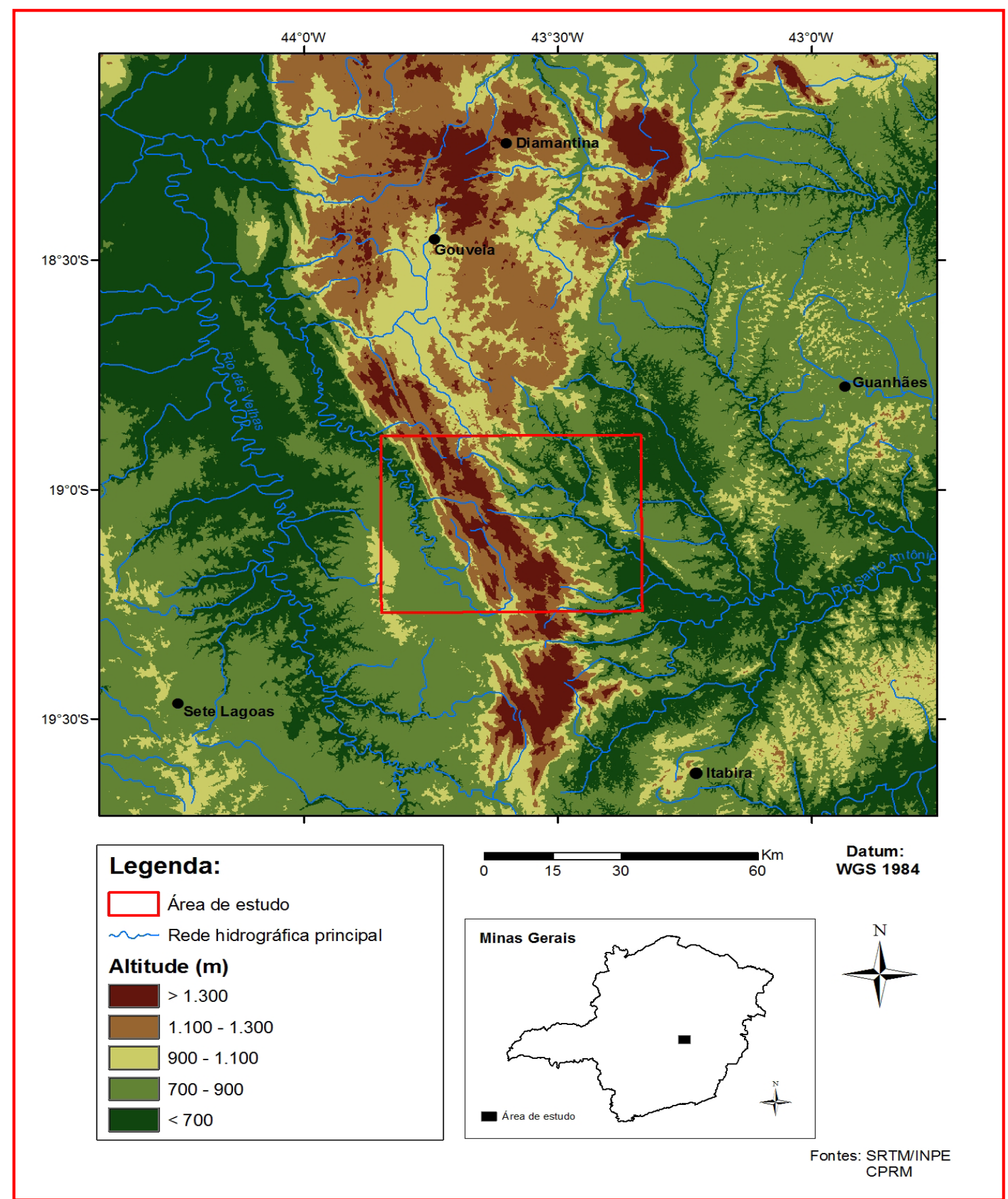

Figura 1: Mapa hipsométrico e localização da área de estudo no contexto da Serra do Espinhaço Meridional. 
Geomorfologicamente, a Serra do Espinhaço constitui parte de um grande escarpamento que separa o interior continental da fachada atlântica e configura o divisor hidrográfico da bacia do Rio São Francisco com as bacias hidrográficas costeiras. Esse escarpamento demarca significativa diferenciação altimétrica entre as superfícies mais elevadas localizadas no interior continental, daquelas mais rebaixadas que ocupam a fachada atlântica (VALADÃO, 2009).
Neves et al. (2005) caracteriza o clima da Serra do Espinhaço Meridional como sendo fortemente influenciado pelo fator orográfico, onde as zonas externas mostram um significativo aumento da temperatura média anual. O clima da região é mesotérmico, Cwb na classificação de Koppen, caracterizado por verões brandos e úmidos (outubro a abril), invernos mais frescos e secos (junho a agosto) e curtas transições nos meses de maio e setembro. A precipitação e a temperatura médias anuais variam de $1250 \mathrm{~mm}$ a $1550 \mathrm{~mm}$ e $18^{\circ}$ a $19^{\circ} \mathrm{C}$, respectivamente.

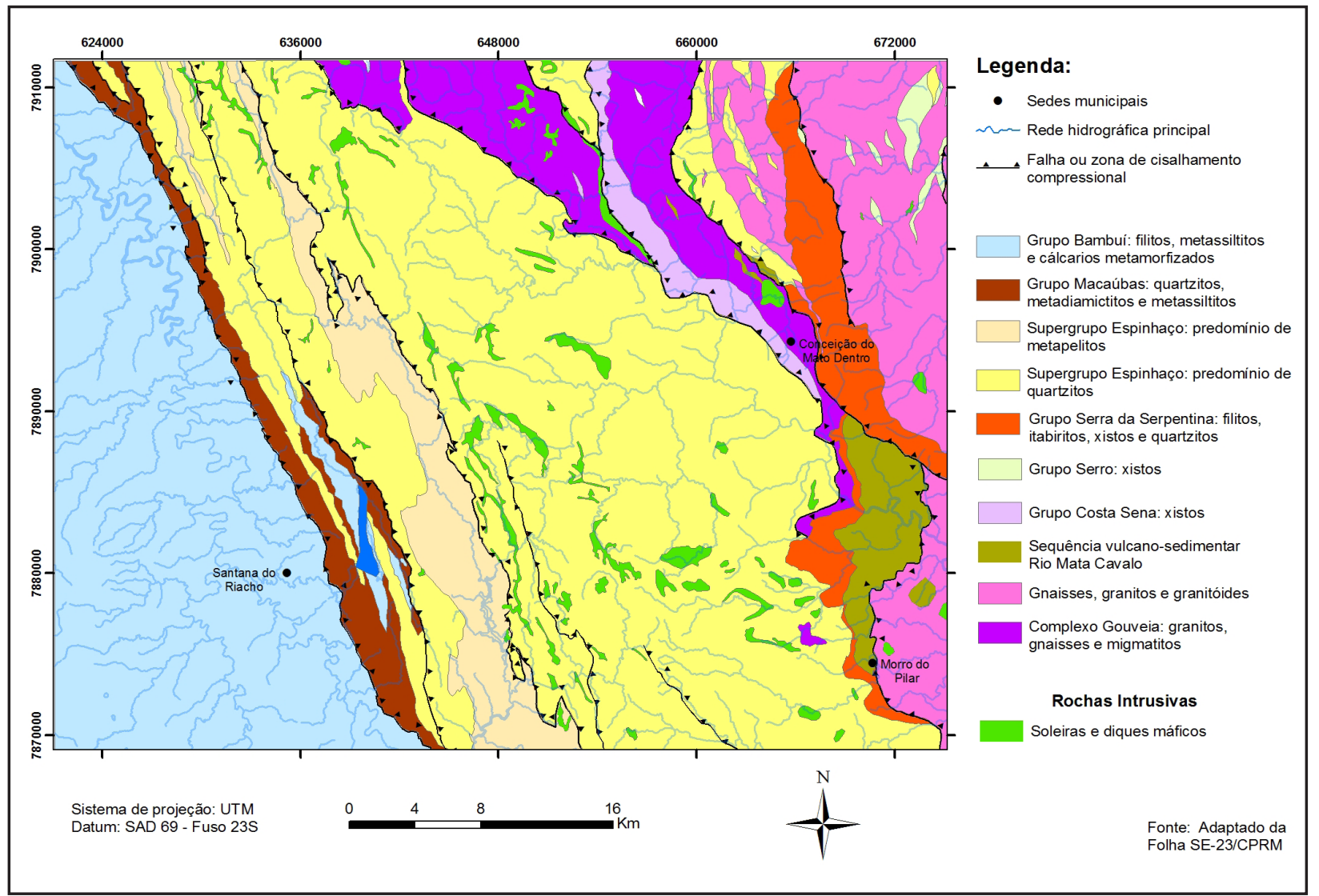

Figura 2: Mapa Geológico simplificado da área de estudo.

Em estudos realizados na Serra do Cipó, Valente (2009) afirma que naquele ambiente predominam solos arenosos rasos e afloramentos rochosos. Muitas vezes, o perfil constitui-se de apenas uma camada orgânica sobre a rocha. Onde ocorrem rochas metapelíticas ou 
metabásicas os solos são bem mais desenvolvidos, argilosos e igualmente distróficos, apresentando horizontes $\mathrm{A}$ espessos e ricos em matéria orgânica. Nas extremidades leste e oeste da área de estudo, as características litológicas favorecem o intemperismo e consequentemente a formação de solos mais profundos.

De acordo com Gontijo (2008), o Espinhaço Meridional surge como um grande divisor de biomas, comportando um mosaico fitofisionômico e florístico. A encosta oriental abriga a floresta estacional semi-decidual, pertencente ao bioma da Mata Atlântica. Já a borda ocidental é marcada pela vegetação típica de cerrado. Os campos rupestres de altitude aparecem como faixas de transição ou refúgios isolados em meio aos domínios maiores.

\section{Procedimentos metodológicos}

A elaboração do mapeamento teve como base os procedimentos técnico-operacionais propostos pelo IBGE (2009) em seu Manual Técnico de Geomorfologia, utilizado como referência pelo Instituto para mapear o relevo brasileiro. Foram incorporadas ainda, contribuições metodológicas de Ross (1992) e Florenzano (2008). No entanto, a metodologia foi adaptada de acordo com os objetivos propostos e particularidades da área de estudo, buscando, sempre que possível, empregar referências de topônimos locais à nomenclatura das unidades de relevo. Também buscou-se dar sequência à sistematização adotada por Silva \& Salgado (2009) e Marent \& Salgado (2010) em mapeamentos de unidades de relevo realizados no Quadrilátero Ferrífero.

No mapeamento foi empregado o terceiro nível taxonômico proposto pelo IBGE (2009), denominado Unidades Geomorfológicas e definido como um arranjo de formas altimétrica e fisionomicamente semelhantes em seus diversos tipos de modelados. As unidades de relevo foram individualizadas a partir da análise integrada de cartas temáticas que permitiram observar variações na morfologia, na altimetria, na declividade, na litoestrutura e na organização da rede de drenagem. De modo a seguir a taxonomia do mapeamento geomorfológico proposta pelo IBGE
(2009) foram também delimitados os Domínios Morfoestruturais, referentes ao primeiro táxon e as Regiões geomorfológicas, que correspondem ao segundo táxon.

As atividades de gabinete foram compostas inicialmente, por pesquisa bibliográfica sobre a área de estudo e técnicas de mapeamento de relevo. A etapa de cartografia digital processada no software ArcGis 9.2 se baseou na utilização de produtos SRTM (Shuttle Radar Topography Mission) refinados pelo projeto TOPODATA do Instituto Nacional de Pesquisas Espaciais. De acordo com Carvalho \& Bayer (2008) essas imagens de radar, capazes de reproduzir altitudes, são adequadas para fins de mapeamentos geomorfológicos em pequenas e médias escalas. Utilizando-se os modelos digitais de elevação da SRTM, podem ser gerados dados de grande valia no mapeamento, como perfis topográficos, sombreamento do relevo, mapas hipsométricos e mapas de declividade.

No cruzamento dos dados foram utilizadas as seguintes bases cartográficas digitais: (i) mapeamento geológico do Projeto Espinhaço na escala de 1:100.000 (GROSSI-SAD et al., 1997); (ii) curvas de nível e rede de drenagem obtidas através da digitalização de cartas topográficas do IBGE na escala de 1:100.000 pelo Projeto Geominas. Também foi empregada imagem de satélite Landsat 7 ETM+ (composição colorida 457, RGB). Ainda como apoio ao mapeamento foram utilizadas imagens de alta resolução disponibilizadas pelo software Google Earth. De modo a complementar as informações obtidas em gabinete, foram realizados trabalhos de campo para registro fotográfico, observação das coberturas superficiais e descrição da paisagem.

\section{Resultados e Discussão}

Previamente foram identificados dois domínios morfoestruturais, referentes ao maior táxon na compartimentação do relevo: (i) Cráton do São Francisco e (ii) Cinturão Orogênico do Atlântico. No segundo nível hierárquico, denominado Regiões Geomorfológicas, foram individualizados três compartimentos: (i) Depressão Interplanáltica do Alto São Francisco; (ii) Serra do Espinhaço e (iii) Planaltos do Alto Rio Doce. 


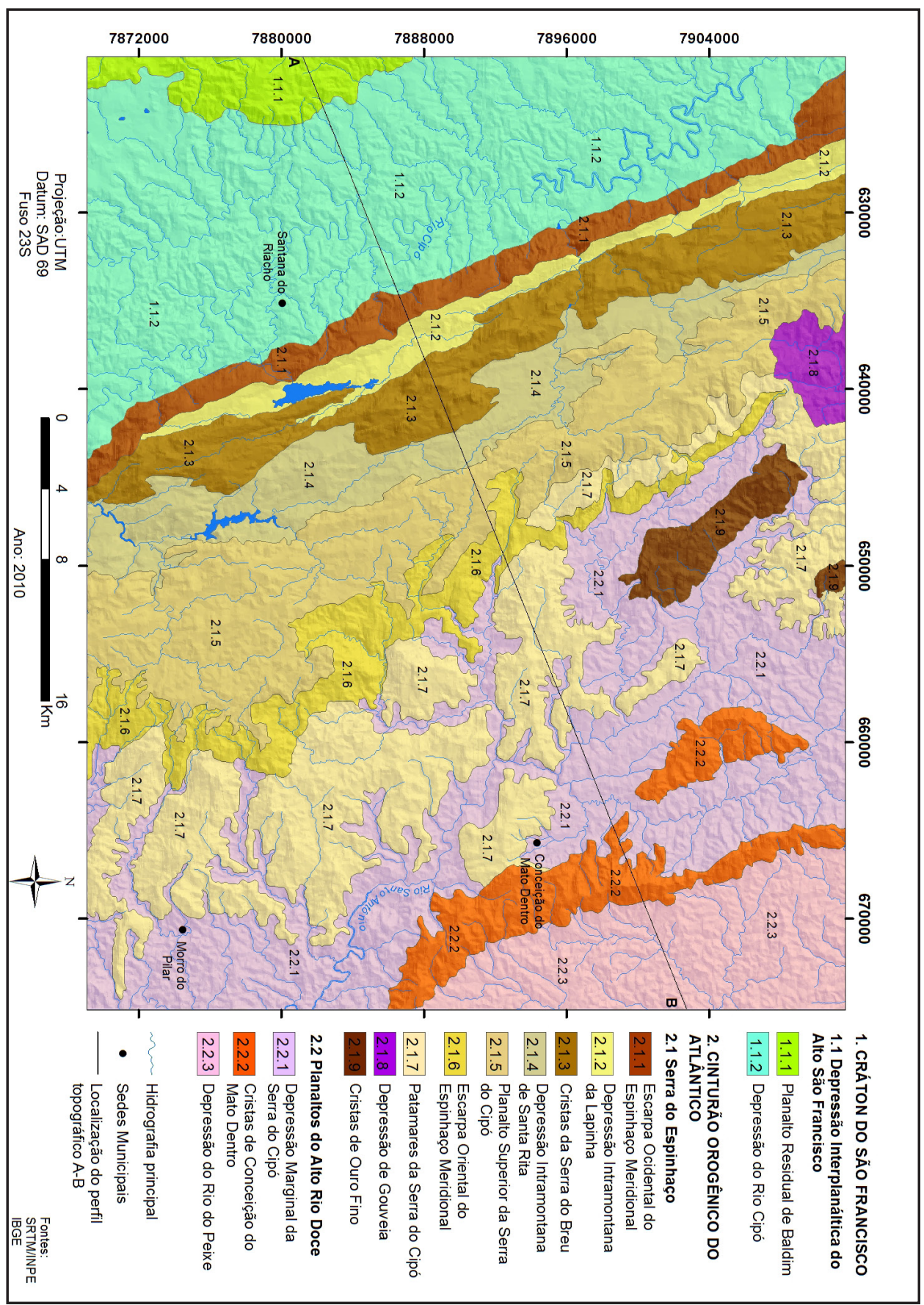

Figura 3: Mapa de unidades de relevo. 
De acordo com o IBGE (2009) os conjuntos de formas de relevo que compõem as Unidades Geomorfológicas constituem compartimentos identificados como planícies, depressões, tabuleiros, chapadas, patamares, planaltos e serras $\mathrm{Na}$ área de estudo, foram delimitadas quatorze unidades distribuídas entre depressões, patamares, planaltos e serras, sendo que essas últimas foram aqui divididas em cristas e escarpas, buscando uma melhor adequação do mapeamento às características geomorfológicas regionais (Fig. 3). A maior parte das unidades está no perfil topográfico apresentado na Fig. 4. Esse perfil tem direção ESE-WNW e, portanto, cruza perpendicularmente as estruturas associadas ao cinturão de cavalgamentos.

A unidade Planalto Residual de Baldim corresponde ao divisor hidrográfico entre as bacias do Rio das Velhas, a oeste e do Rio Cipó, a leste. Sustentada essencialmente pelos metassiltitos da Formação Lagoa do Jacaré, esta elevação possui direção aproximada N-S e se encontra delimitada por escarpas com cerca de $200 \mathrm{~m}$. Predominam topos extensos posicionados entre $1050 \mathrm{~m} \mathrm{e}$ 1100 m de altitude. Em direção ao sul os calcários metamorfizados passam a predominar frente aos metassiltitos, o que provoca dissecação mais intensa e decréscimo nas altitudes.

A Depressão do Rio Cipó encontra-se alojada entre o Planalto Residual de Baldim e a Escarpa Ocidental do Espinhaço Meridional (Fig. 5). Nessa unidade esculpida sobre os filitos e metassiltitos da Formação Serra de Santa Helena predomina um modelado composto por morros e morrotes de topos convexos e alongados. Na porção centro-sul da unidade os topos estão posicionados entre $800 \mathrm{~m}$ e $900 \mathrm{~m}$ de altitude, enquanto no extremo norte estes raramente superam $800 \mathrm{~m}$. Suas vertentes intercalam trechos levemente convexizados que frequentemente ultrapassam 20 $\%$ de declividade e trechos côncavos, que abrigam as inúmeras cabeceiras de drenagem. Essa unidade apresenta a maior densidade de drenagem da área mapeada. Em alguns pontos próximos da calha do Rio Cipó o relevo suaviza-se, bem como nas áreas onde a litologia predominante são os calcários metamorfizados.

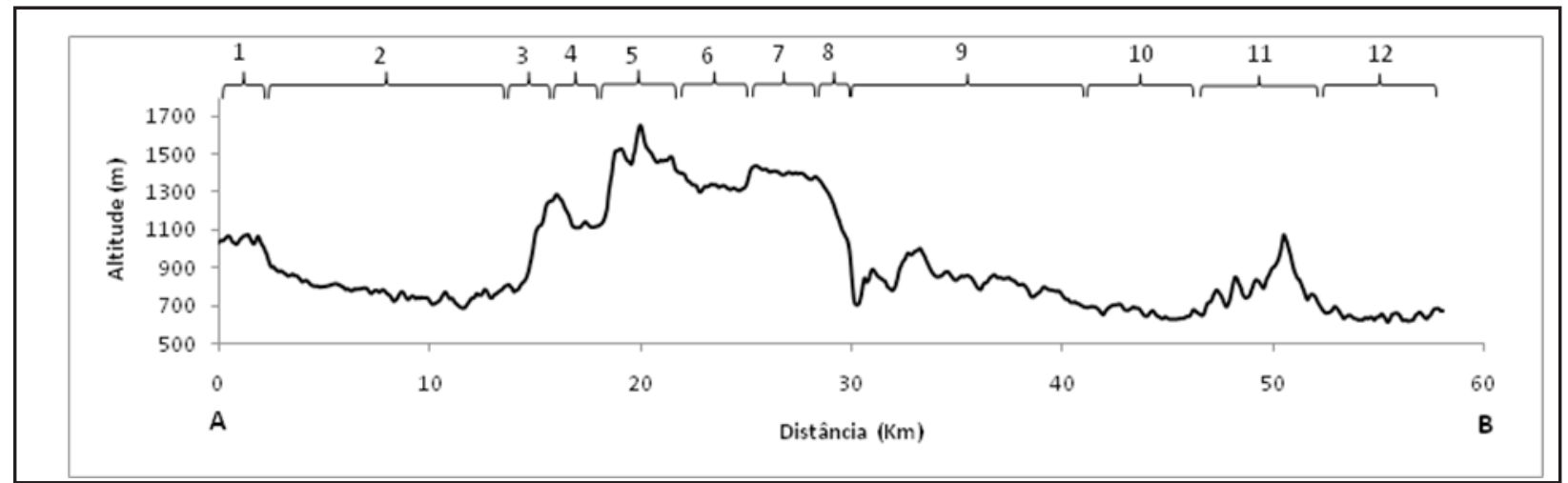

Figura 4: Perfil Topográfico A-B de direção ESE-WNE

1: Planalto Residual de Baldim; 2: Depressão do Rio Cipó; 3: Escarpa Ocidental do Espinhaço Meridional;

4: Depressão Intramontana da Lapinha; 5: Cristas da Serra do Breu; 6: Depressão Intramontana de Santa Rita; 7: Planalto Superior da Serra do Cipó; 8: Escarpa Oriental do Espinhaço Meridional; 9: Patamares da Serra do Cipó; 10: Depressão Marginal da Serra do Cipó; 11: Cristas de Conceição do Mato Dentro; 12: Depressão do Rio do Peixe. 


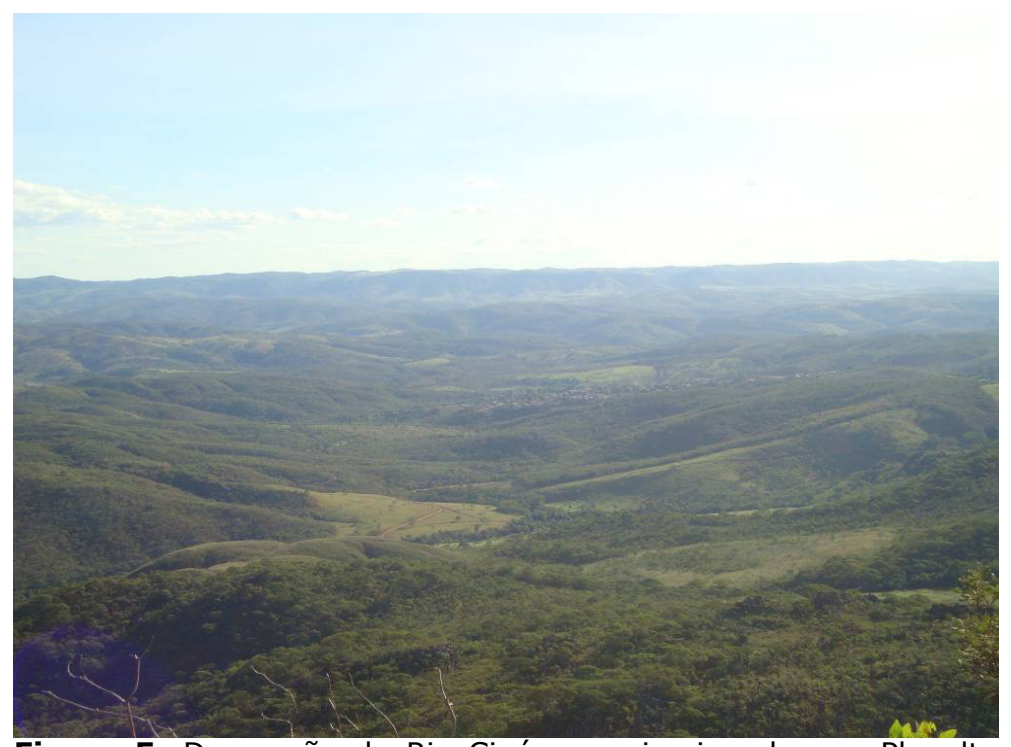

Figura 5: Depressão do Rio Cipó em primeiro plano e Planalto Residual de Baldim ao fundo, vistos da Escarpa Ocidental da Serra do Cipó.

A unidade Escarpa Ocidental do Espinhaço Meridional marca o limite oeste da referida serra (Fig. 6). Corresponde à frente de empurrão gerada durante a Orogênese Brasiliana, que forma o contato estrutural entre a faixa de dobramentos Araçuaí e a borda sudeste do Cráton do São Francisco (SAADI et al., 2002). Essa imponente feição, de altura média superior a 400 $\mathrm{m}$, apresenta drenagem anaclinal, sendo inclusive seccionada por algumas gargantas. Tal escarpa de linha de falha (SAADI et al., 2002) é sustentada por quartzitos do Grupo Macaúbas e do Supergrupo Espinhaço (Formação Córrego dos Borges).

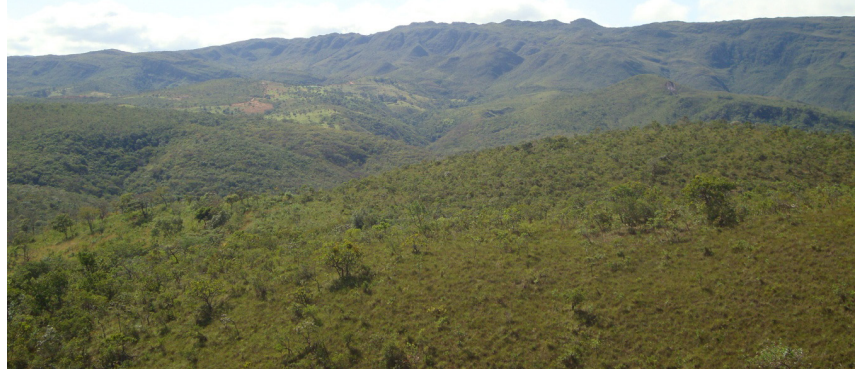

Figura 6: Escarpa Ocidental do Espinhaço Meridional vista da Depressão do Rio Cipó. 
Limitada a ENE pelas Cristas da Serra do Breu, a Depressão Intramontana da Lapinha abrange o reverso da escarpa ocidental e os vales ortoclinais dos córregos Cachoeira, Fundo, Lapinha, Mata-Capim e da Vargem, além do baixo curso do Ribeirão Soberbo (Fig. 7). A incisão fluvial ao longo do estreito eixo da depressão é facilitada pela fragilidade dos calcários da Formação Sete Lagoas, presentes no sul da unidade, e dos metapelitos da Formação Córrego da Bandeira, que ocorrem mais ao norte. No piso da depressão a altitude gira em torno de $1100 \mathrm{~m}$ e as declividades são bastante suaves, embora sofram considerável aumento nas proximidades da garganta em que o Rio das Pedras atravessa a Escarpa Ocidental, constituindo uma das saídas da rede de drenagem aprisionada no interior da depressão.

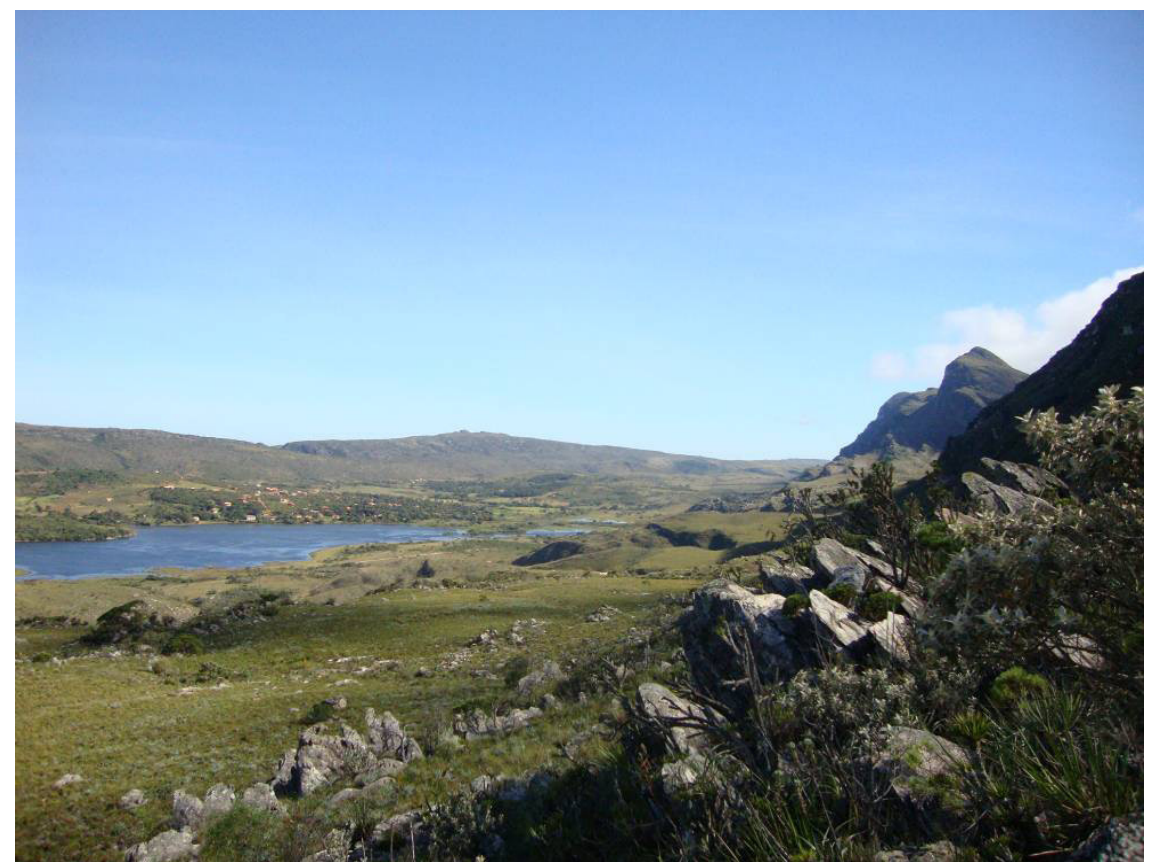

Figura 7: Depressão Intramontana da Lapinha ao centro, com o reverso da escarpa ocidental ao fundo, vistos das Cristas da Serra do Breu.

A unidade Cristas da Serra do Breu é composta por alinhamentos de cristas assimétricas sustentadas, em sua maior parte, por quartzitos da Formação Galho do Miguel (Fig. 7 e 8). Essas elevações possuem face escarpada voltada para WSW que coincide com a frente dos empurrões e reverso formado por rampas de menor declividade concordantes com o mergulho geral do acamamento e/ou da foliação. Essas cristas são intercaladas por alguns vales profundos, muitas vezes adaptados a lineamentos estruturais. É a unidade que apresenta as maiores altitudes da área mapeada, com ponto culminante a 1687 m no pico do Breu. Em geral, os topos são angulosos, com exceção de um pequeno trecho no norte da unidade, onde encontramse ligeiramente aplainados e conectados mais suavemente a Depressão Intramontana de Santa Rita.

A Depressão Intramontana de Santa Rita recebe o nome da formação geológica predominante em sua área de abrangência ${ }^{1}$ (Fig. 8). Os metapelitos desta formação condicionam um relevo formado por colinas suaves que apresentam baixa intensidade de aprofundamento da drenagem. Esta unidade está alojada entre as Cristas da Serra do Breu e o Planalto Superior da 
Serra do Cipó, abrigando a maior parte das bacias hidrográficas do Rio Preto, do Ribeirão Soberbo, do Rio das Pedras e do Rio Parauninha. A altitude média é de cerca de $1250 \mathrm{~m}$ e as declividades são quase sempre inferiores a $15 \%$. No extremo sul da unidade, próximo do ponto onde o Rio Parauninha cruza a escarpa ocidental, a altitude decai significativamente, enquanto as declividades sofrem considerável aumento.

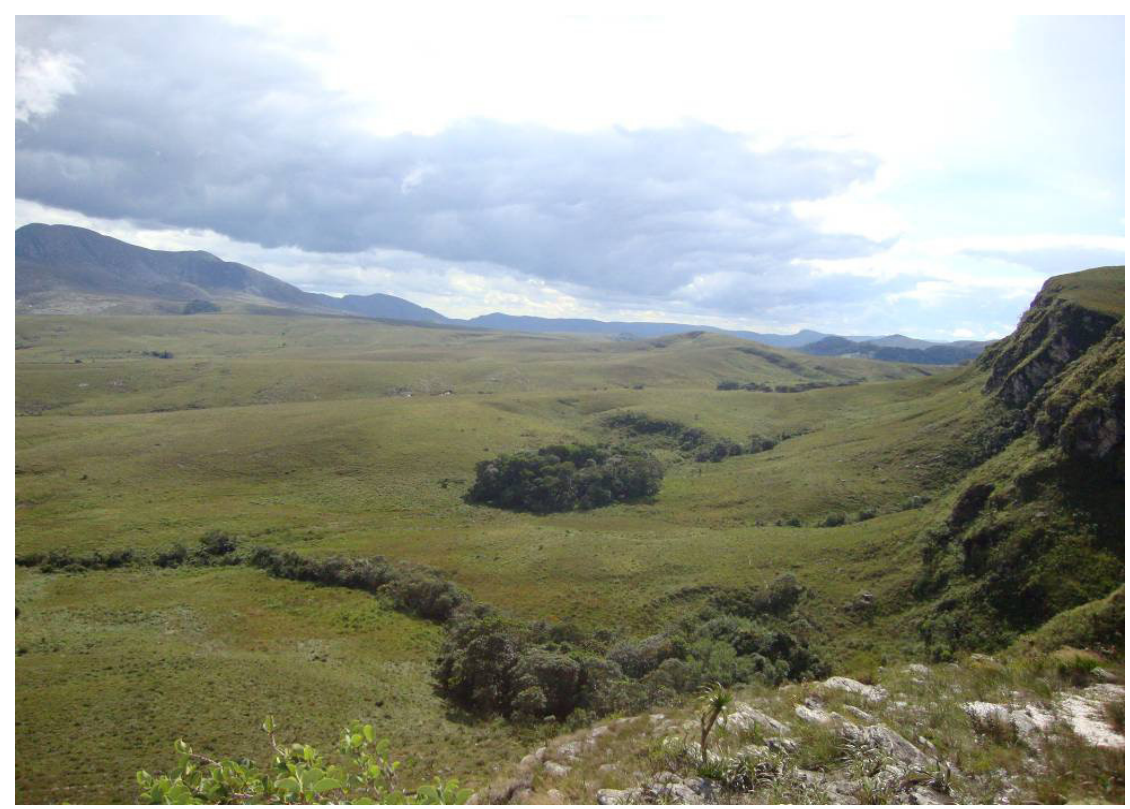

Figura 8: Depressão Intramontana de Santa Rita ao centro, com Cristas da Serra do Breu à esquerda e Planalto Superior da Serra do Cipó à direita.

\section{O Planalto Superior da Serra do Cipó} é limitado por escarpas, rampas e pequenos patamares, alguns deles foram reunidos a esta unidade por questão de escala. No entanto, a morfologia dominante é formada por platôs quartzíticos levemente dissecados, posicionados entre $1350 \mathrm{~m}$ e $1450 \mathrm{~m}$ de altitude. Há amplo predomínio de quartzitos da Formação Galho do Miguel, enquanto a Formação Sopa-Brumadinho (Unidade Serra do Lobo) ocorre de modo mais restrito no sul da unidade. As duas formações são entrecortadas por diques e soleiras de rochas metabásicas. Esta unidade abriga o importante divisor hidrográfico que limita a bacia do Rio São Francisco, a oeste, e a bacia do Rio Doce, a leste.

A Depressão de Gouveia corresponde, na área mapeada, à alta bacia do Ribeirão Congonhas, um dos principais afluentes do Rio
Paraúna, sendo que este corresponde ao nível de base da depressão. A unidade tem como substrato predominante os granitos, gnaisses e migmatitos do Complexo Gouveia. Essa pequena porção da depressão é composta por morros e morrotes de topos convexos, posicionados entre 1100 e $1200 \mathrm{~m}$, no entanto, as altitudes e declividades decrescem significantemente em direção ao centro da depressão, que se encontra fora da área mapeada.

A unidade Escarpa Oriental do Espinhaço Meridional (Fig. 9) possui traçado irregular, se diferenciando do caráter morfotectônico apresentado pelo escarpamento ocidental (SAADI, 1995). Aparentemente, a evolução dessa escarpa esta relacionada, de modo mais direto, ao forte recuo erosivo das cabeceiras de diversos afluentes da margem direita Rio Santo Antônio. No entanto, 
a participação da denudação diferencial também pode ser observada, já que essa feição está frequentemente associada ao contato entre as unidades litológicas que sustentam o Planalto Superior da Serra do Cipó (Formação Galho do Miguel e unidade Serra do Lobo) e as unidades mais frágeis que ocupam as porções adjacentes menos elevadas (unidades Itambé do Mato Dentro, Rio Preto e Rio Preto - nível fosfatado), conforme observado por Rezende et al. (no prelo). Com amplitude altimétrica variável entre $300 \mathrm{~m}$ e 600 $\mathrm{m}$, a expressão morfológica dessa unidade alternase entre paredões abruptos, degraus escalonados, cânions e rampas de menor declividade.

A unidade Patamares da Serra do Cipó é a que apresenta a maior diversidade morfológica e altimétrica. Sua principal característica é constituir um nível intermediário entre o Planalto
Superior da Serra do Cipó e a Depressão Marginal da Serra do Cipó. (Fig. 11). A ocorrência mais comum desses patamares é na forma de esporões interfluviais, que constituem saliências em meio a Depressão Marginal da Serra do Cipó. Esses morros de topos alongados são elaborados, sobretudo, nos metassedimenos das unidades Rio Preto e Conceição do Mato Dentro. No extremo norte e no extremo leste desta unidade o substrato predominante passa a ser formado pelos granitos e gnaisses do Complexo Gouveia e pelos xistos do Grupo Costa Sena. Em geral as altitudes decrescem de oeste para leste, variando entre 1300 e 800 $\mathrm{m}$. A declividade das vertentes frequentemente ultrapassa $20 \%$. Nas proximidades do cânion do Peixe Tolo esta unidade se manifesta na forma de um degrau (1000-1200 m) posicionado entre o Planalto Superior da Serra do Cipó e a Escarpa Oriental.

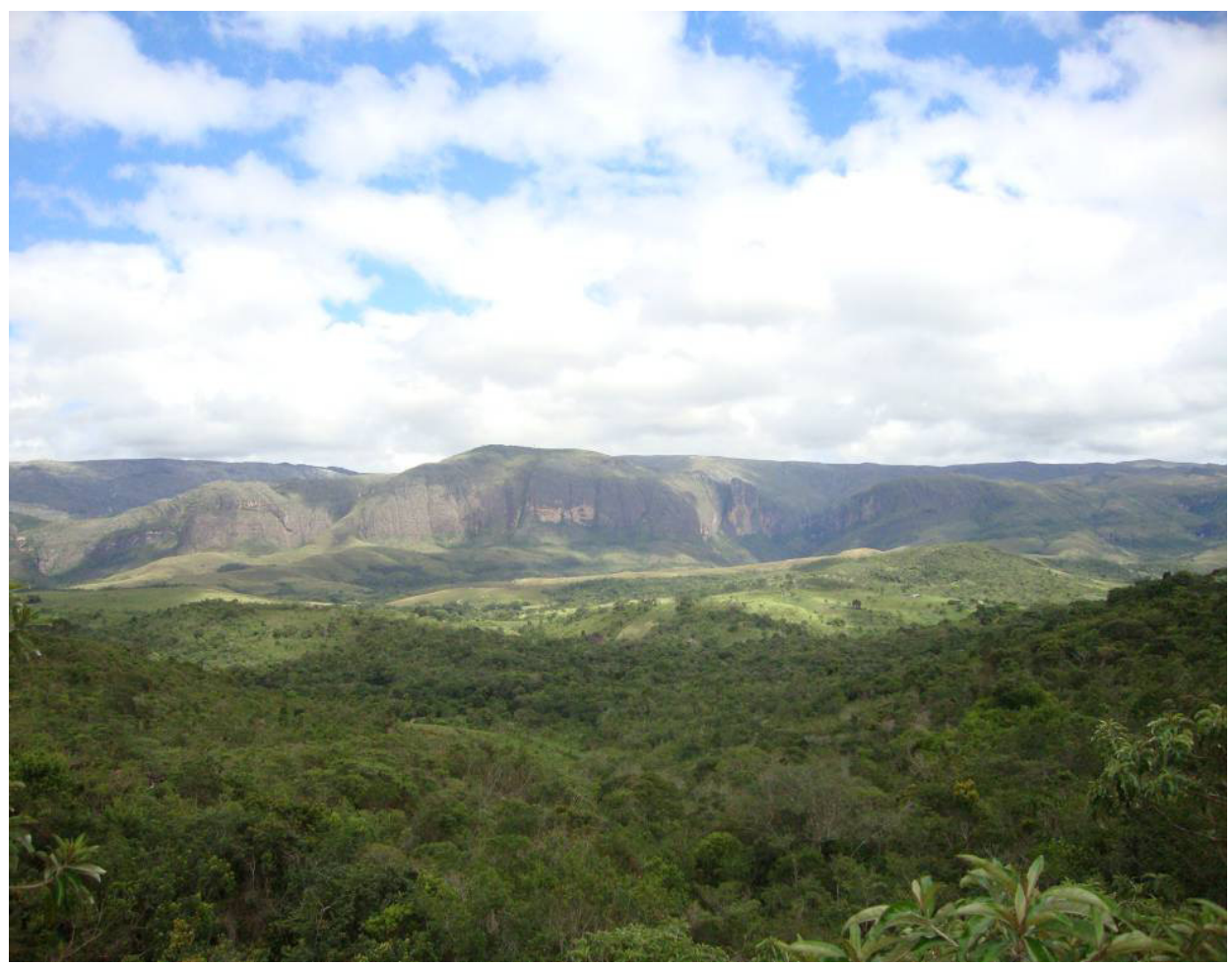

Figura 9: Em primeiro plano está a Depressão Marginal da Serra do Cipó e ao fundo a Escarpa Oriental, vistas a partir das Cristas de Ouro Fino. 
A unidade Cristas de Ouro Fino é composta por dois alinhamentos de cristas assimétricas sustentadas por quartzitos e metaconglomerados da Formação SopaBrumadinho (Fig. 10). O principal alinhamento corresponde ao divisor hidrográfico entre a alta bacia dos rios Parauninha ${ }^{2}$ e Lambari, sendo localmente denominado Serra Ouro Fino, Serra da Penha e Serra da Gurita. O segundo alinhamento está localizado no extremo norte da área mapeada, embutido nos Patamares da Serra do Cipó, e recebe a denominação local de Serra da Bocaina. Ambos ultrapassam $1200 \mathrm{~m}$ de altitude nas porções mais elevadas de seus topos aguçados, embora a altitude média seja inferior a este valor. As vertentes voltadas para SSW são escarpadas, denotando o controle imposto pelas frentes de empurrão, enquanto os reversos possuem declividades menos acentuadas.

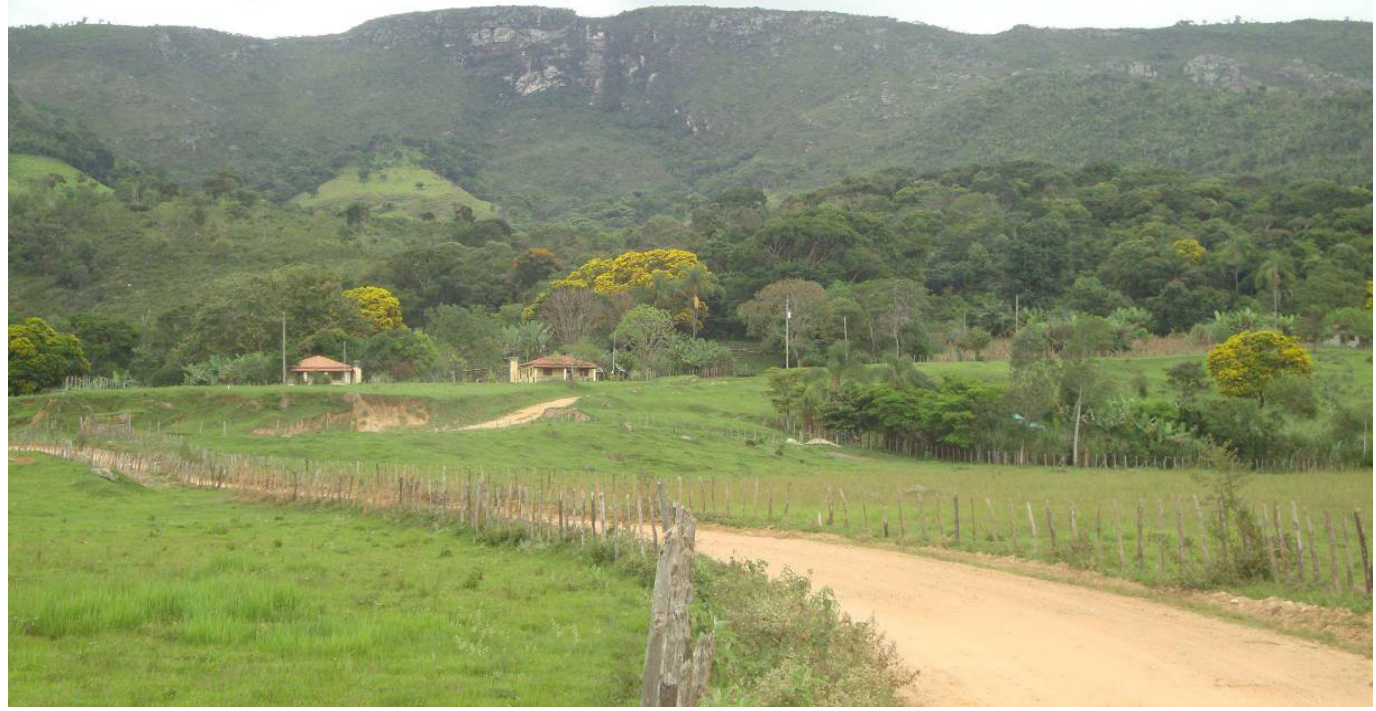

Figura 10: Cristas de Ouro Fino (face NE) vista da Depressão Marginal da Serra do Cipó.

A Depressão Marginal da Serra do Cipó bordeja o leste faixa serrana, acompanhando o trajeto do alto Rio Santo Antônio e de seus principais afluentes, com destaque para o Rio Parauninha (Fig. 9, 10 e 11). Muitos desses cursos fluviais penetram irregularmente os patamares e até mesmo a escarpa oriental, formando corredores rebaixados em meio aos morros de topos alongados. Esta unidade está sobre substrato geológico bastante variado, abrangendo tanto metassedimentos do Supergrupo Espinhaço quanto rochas arqueanas dos complexos Gouveia e Dona Rita. Morfologicamente predominam morrotes com encostas declivosas, enquanto planícies fluviais ocorrem de modo mais restrito, ao longo dos principais cursos d'água. As altitudes estão entre $550 \mathrm{~m}$ e $750 \mathrm{~m}$. 


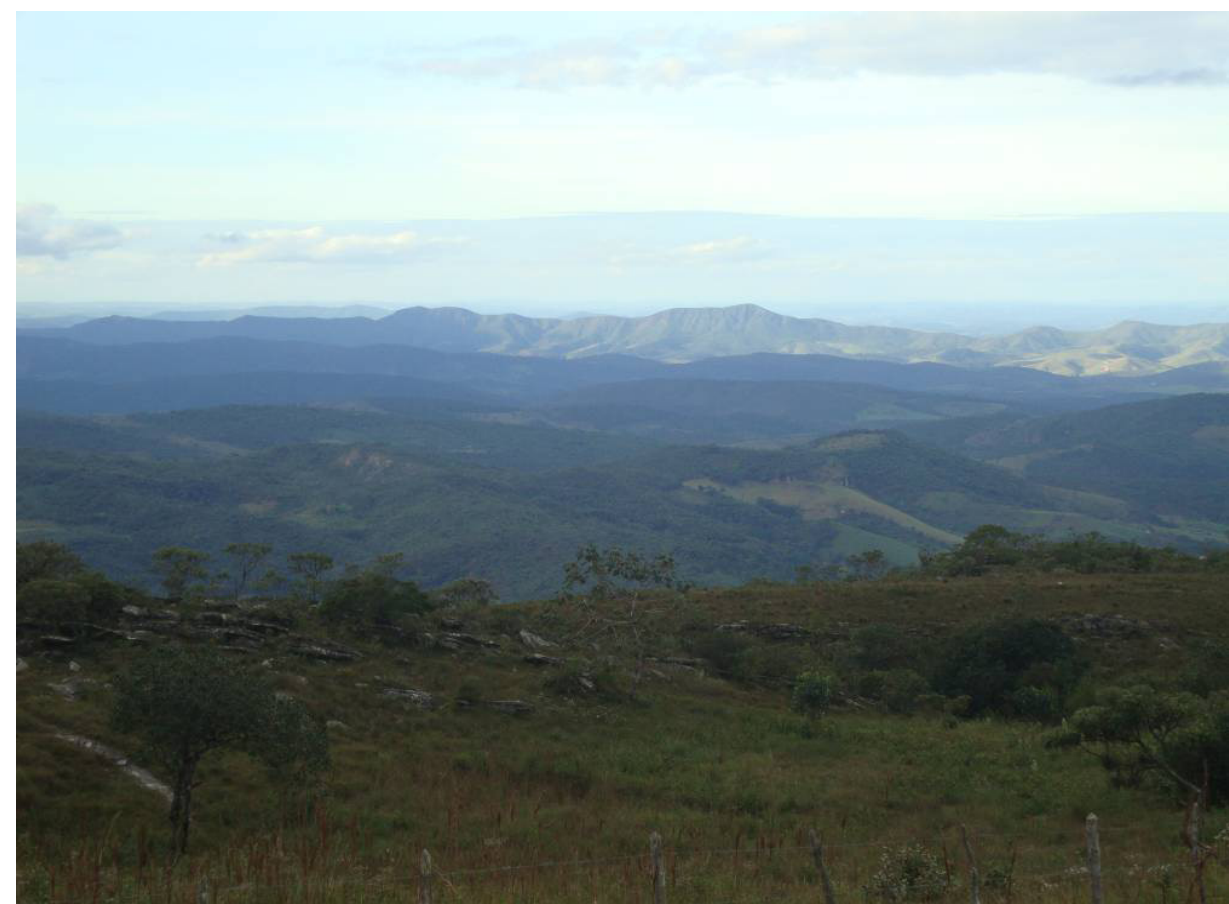

Figura 11: No primeiro plano está o Planalto Superior da Serra do Cipó, de onde foi tirada a foto. No segundo plano avista-se a os Patamares e a Depressão Marginal, ao fundo se encontram as Cristas de Conceição do Mato Dentro.

A unidade Cristas de Conceição do Mato Dentro é formada por dois alinhamentos de cristas concordantes com a direção de diversas falhas de empurrão (Figs. 2 e 11). O mais ocidental desses alinhamentos é localmente denominado Serra do Pinho e possui a forma de um arco com concavidade voltada para leste no qual as altitudes decaem em direção as extremidades norte e sul. Essa elevação possui altitude máxima de $1030 \mathrm{~m}$ e tem como substrato predominante os quartzitos das formações São João da Chapada e Sopa Brumadinho.

O segundo alinhamento pertencente às Cristas de Conceição do Mato Dentro corresponde a um extenso hogback de direção NNW-SSE, que passa a NW-SE em sua porção meridional. As altitudes máximas ultrapassam 1150 m, sendo sustentadas pelas unidades quartzíticas e itabiríticas do Grupo Serra da Serpentina. Nas proximidades da cidade de Conceição do Mato
Dentro seu topo anguloso se bifurca em duas linhas de cumeada paralelas que seguem em direção SE. Essa faixa serrana recebe diversas denominações locais como Serra do Sapo, Serra da Ferrugem e Serra da Mina. Além disso, corresponde ao divisor hidrográfico entre as bacias dos Rios Santo Antônio, a oeste e do Rio do Peixe, a leste.

A Depressão do Rio do Peixe coincide aproximadamente com a bacia hidrográfica do referido rio. Essa unidade é limitada a oeste pelas Cristas de Conceição do Mato Dentro e a leste por um planalto intensamente dissecado que encontrase fora da área mapeada. A litologia é composta predominantemente por ortognaisses arqueanos do Complexo Dona Rita. Morfologicamente predominam morrotes de topos convexos e vertentes com declividades superiores a $15 \%$. A altitude média dos topos está entre $700 \mathrm{~m}$ e $750 \mathrm{~m}$.

Embora o quarto nível taxonômico proposto pelo IBGE (2009), denominado Modelados, não 
tenha sido empregado no presente mapeamento, vale citar que na área de estudo ocorre predomínio absoluto dos modelados de dissecação, notadamente os de dissecação estrutural. Os modelados de acumulação se limitam a planícies e terraços fluviais restritos. As poucas ocorrências de modelados de dissolução correspondem às formas cársticas elaboradas sobre os calcários metamorfizados do Grupo Bambuí. Na atual configuração geomorfológica da área mapeada não foram encontradas ocorrências de modelados de aplanamento.

\section{Considerações Finais}

A partir da proposta de mapeamento de unidades de relevo apresentada é possível elaborar algumas considerações gerais que contribuam nas investigações a respeito da complexa evolução geomorfológica da Serra do Espinhaço Meridional e áreas adjacentes. As formas de relevo da área são fruto de uma série de condicionantes morfoestruturais e morfotectônicos, que em convergência com os processos de denudação diferencial deram origem a uma enorme diversidade fisiográfica, ressaltando o papel da Serra do Espinhaço como um importante divisor morfo-bio-climático.

Destaca-se a resistência diferenciada das diversas litologias frente aos processos denudacionais, enquanto os quartzitos, principalmente das formações Galho do Miguel e Sopa-Brumadinho, sustentam as unidades de cristas e o Planalto Superior da Serra do Cipó, as rochas mais frágeis, como metapelitos e gnaisses, comumente ocupam depressões que acompanham a direção geral da faixa serrana central (NNW-SSE). Um excelente exemplo ocorre na Depressão Intramontana de Santa Rita, onde a predominância de metapelitos colocou essa unidade em patamar altimétrico bastante inferior às elevações quartzíticas adjacentes.

A disposição geral das unidades de relevo é concordante com a direção da faixa orogênica pré-cambriana, refletindo o forte controle litoestrutural imposto ao relevo regional. Esse controle litoestrutural só perde importância na borda leste, onde o forte recuo erosivo dos afluentes do Rio Santo Antônio criou uma série de reentrâncias e saliências topográficas discordantes do trend principal.

Gargantas, vales intensamente encaixados, terraços fluviais escalonados e escarpas retilíneas são algumas das evidências da influência da atividade neotectônica na geomorfogênese regional. Esse controle exercido pela tectônica recente possivelmente se relaciona ao reconhecido soerguimento Neógeno das margens do Cráton do São Francisco (SAADI, 1995; SAADI \& COSTA, 1999; VALADÃO, 2009).

\section{Agradecimentos}

Agradecemos o apoio financeiro da FAPEMIG e do CNPq.

\section{Notas}

1. Na denominação desta unidade não foi possível empregar um topônimo local devido à ausência de uma localidade (vila, fazenda, etc.) ou mesmo de um curso fluvial que drenasse a maior parte da área.
2. Não confundir com o rio de mesmo nome citado anteriormente, já que este se encontra inserido na unidade Depressão Intramontana de Santa Rita.
ABREU, A. A. Análise geomorfológica: reflexão e aplicação: Uma contribuição ao conhecimento das formas de relevo do Planalto de Diamantina-MG. 1982, 296 f. Tese (Livre Docência) - Departamento

\section{Bibliografia}

de Geografia, Universidade de São Paulo, São Paulo, 1982.

ALMEIDA-ABREU, P. A. O Supergrupo Espinhaço da Serra do Espinhaço Meridional (Minas Gerais): 
o Rifte, a Bacia e o Orógeno. Geonomos, Belo Horizonte, v. 3, n. 1, p. 1-18, 1995.

ALMEIDA-ABREU, P. A.; RENGER, F. E. Serra do Espinhaço Meridional: um orógeno de colisão do Mesoproterozóico. Revista Brasileira de Geociências, São Paulo, v. 32, n. 1, p. 1-14, 2002.

CARVALHO, T. M; BAYER, M. Utilização dos produtos da "Shuttle Radar Topography Mission" (SRTM) no mapeamento geomorfológico do Estado de Goiás. Revista Brasileira de Geomorfologia, Goiânia, v. 9, n. 1, p. 35-41, 2008.

FLORENZANO, T. G. Cartografia. In: FLORENZANO, T. G. (Org.). Geomorfologia: Conceitos e tecnologias atuais. 1 ed. São Paulo: Oficina de Textos, 2008, p. $105-128$.

FONSECA, B. M.; AUGUSTIN, C. H. R. R.; MOURA, A. C. M. O Uso do Geoprocessamento para o Mapeamento Geomorfológico da Serra do Espinhaço Meridional. In: SIMPÓSIO NACIONAL DE GEOMORFOLOGIA, 7, 2008, Belo Horizonte. Anais do... Belo Horizonte: UGB, 2008. CD-ROM.

GONTIJO, B. M. Uma geografia para a Cadeia do Espinhaço. Megadiversidade. v. 4, n. 1-2, p. 7-15, 2008.

GonTIJO, A. H. F. O Relevo da Serra do Cipó, Espinhaço Meridional. 1993, 118 f. Dissertação (Mestrado) - Departamento de Geografia, Universidade de São Paulo, São Paulo, 1993.

GROSSI-SAD, J. H.; LOBATO, L. M.; PEDROSASOARES, A. C.; SOARES-FILHO, B. S. (coordenadores e editores). Projeto Espinhaço em $C D-R O M$ (textos, mapas e anexos). Belo Horizonte: COMIG - Companhia Mineradora de Minas Gerais. 1997.

IBGE. Manual técnico de geomorfologia. 2. ed. Rio de Janeiro: IBGE, 182 p., 2009.

MARENT, B. R.; SALGADO, A. A. R. Mapeamento das unidades do relevo da porção nordeste do Quadrilátero Ferrífero-MG. Geografias, Belo
Horizonte, v. 6, n. 1, p. 118-139, 2010.

NEVES, S. C.; ALMEIDA-ABREU, P. A.; FRAGA, L. M. S. Fisiografia. In: SILVA, A. C. et al. Serra do Espinhaço Meridional: Paisagens e Ambientes. Belo Horizonte: O Lutador, 2005. p. 47-58.

REZENDE, E. A.; LEÃO, M. R.; SALGADO, A. A. R.; OLIVEIRA, C. K. R.; NALINI JÚNIOR, H. A. A influência litológica nas taxas de denudação geoquímica do médio Espinhaço Meridional/MG. Sociedade e Natureza. No prelo 2011.

ROSS, J. L. S. O registro cartográfico dos Fatos Geomórficos e a Questão da Taxonomia do Relevo, Revista do Departamento de Geografia, FFLCHUSP, São Paulo, n.6, p.17-29, 1992.

SAADI, A. A geomorfologia da Serra do Espinhaço em Minas Gerais e de suas margens. Geonomos, Belo Horizonte, v. 3, n. 1, p. 41-63, 1995.

SAADI, A.; COSTA, R. D. . Morphotectonics of an internal region of passive margin: the Minas Gerais state (Southeastern Brazil). In: REGIONAL CONFERENCE ON GEOMORPHOLOGY, 1999, Rio de Janeiro. Proceedings of Regional Conference on Geomorphology. Rio de Janeiro: União da geomorfologia Brasileira/UFRJ, 1999. v. 1. p. 136-137.

SAADI, A.; MACHETTE, M. N.; HALLER, K. M.; DART, R. L.; BRADLEY, L.; SOUZA, A. M. P. D. Map and Database of Quaternary Faults and Lineaments in Brazil. Denver: USGS, 2002. 59 p.

SILVA, J. R.; SALGADO, A. A. R. Mapeamento das unidades de relevo da região da Serra do Gandarela - Quadrilátero Ferrífero-/MG. Geografias, Belo Horizonte, v. 5, n. 2, p. 107-125, 2009.

VALADÃO, R. C. Geodinâmica de Superfícies de Aplanamento, Desnudação Continental e Tectônica Ativa como condicionantes da Megageomorfologia do Brasil Oriental. Revista Brasileira de Geomorfologia, Uberlândia, v.10, n. 2, p. 77-90, 2009.

VALENTE, E. L. Relações solo-vegetação no Parque 
Nacional da Serra do Cipó, Espinhaço Meridional, Universidade Federal de Viçosa, Viçosa, 2009. Minas Gerais. 2009. 138 f. Tese (Doutorado) - 